\title{
Study on the Mechanical Properties of Tropical Hybrid Cross Laminated Timber Using Bamboo Laminated Board as Core Layer ${ }^{1}$
}

\author{
Nurdiansyah Muhammad GALIH ${ }^{2}$ - Seung Min YANG ${ }^{2}$. \\ Seung Min $\mathrm{YU}^{2} \cdot$ Seog Goo KANG(D) ${ }^{2, \dagger}$
}

\begin{abstract}
This study was performed to analyze the mechanical properties of tropical hybrid cross-laminated timber (CLT) with bamboo laminated board as the core layer in order to evaluate the possibility of its use as a CLT material. Bamboo board was used as the core layer and the tropical species Acacia mangium willd., from Indonesia, was used as the lamination in the outer layer. The modulus of elasticity (MOE), modulus of rupture (MOR), and shear strength of the hybrid CLT were measured according to APA PRG 320-2018 Standard for Performance-Rated Cross-Laminated Timber. The results show that the bending MOE of the hybrid CLT was found to be 2.76 times higher than SPF (Spruce Pine Fir) CLT. The reason why the high MOE value was shown in bamboo board and hybrid CLT applied bamboo board is because of high elasticity of bamboo fiber. However, the shear strength of the hybrid CLT was 0.8 times lower than shear strength of SPF CLT.
\end{abstract}

Keywords: acacia wood, bamboo board, hybrid cross-laminated timber, modulus of elasticity, modulus of rupture, tropical species

\section{INTRODUCTION}

Recently, tall wooden building projects using CLT (Cross Laminated Timber) are increasing in domestic and international. CLT is attracting attention as a material for global warming due to its low specific gravity materials, sustainable natural resources, improved insulation performance, carbon sequestration, lower embodied energy, and low greenhouse gas emission during construction compared to typical concrete building
(Robertson, 2007). In Europe, Canada and Australia, CLT panels have been successfully used in Europe, Canada Australia to construct commercial buildings of 8 floor to 10 floor (MGB et al., 2012). CLT, a large wood panel, was first developed in Europe and is novel building material, used as structural floor, roof, and wall assemblies (ANSI/APA, 2018; Oh et al., 2017; Pang et al., 2017). In the beginning, CLT was developed by stacking lamina orthogonally. In South Korea, studies has been conducted on EVA and nano-clay composites

${ }^{1}$ Date Received September 2, 2019, Date Accepted March 9, 2020

2 Deparment of Biobased Materials, College of Agriculture and Life Science, Chungnam National University, Deajeon 34134, Republic of Korea

† Corresponding author: Seog Goo KANG (e-mail: lachesis@cnu.ac.kr, ORCID: 0000-0002-2440-7070) 
to provide the flame retardant properties, interlayer noise reduction, glulam \& CLT joint, adhesive and bending strength performance of larch CLT (Lee et al., 2017; Lee et al., 2017; Jeong et al., 2016; Choi et al., 2018; Kang et al., 2019; Hong et al., 2017).

In recent year, development of composite CLT using plywood, OSB (Oriented Strand Board), LVL (Laminated veneer lumber) as middle layer has been developed in Korea, USA, and other countries (Chul et al., 2015; Chul et al., 2018; Brandner et al., 2016; Zhiqiang Wang et al., 2017).

The major advantage of CLT is that it is used as a large surface material, so that surface later must meet the structural grade (Gong, 2019). Since the middle layer cores use low grade laminates, it can be used as mixed species as well as increase wood use.

In 2017, 36 korean companies from 14 foreign countries are planting overseas. In particular, 15 out of 36 korean companies are carrying our overseas reforestation project in Indonesia (Korea Forest Service, 2018). The main planting species in Indonesia are Eucalyptus pellita and Acacia mangium, and acacia has a growth rate of $6 \mathrm{~m}^{3} /$ ha higher than eucalyptus (Hegde et al., 2013; Andi et al., 2018). It is reported that available wood production is estimated to be $33 \%$ from the total stand volume of Eucalyptus pellita and $42 \%$ from Acacia mangium plantations assuming that the length of the harvested tress is cut to $2.7 \mathrm{~m}$ and cut to the remaining $1.5 \mathrm{~m}$ (Son et al., 2010).

Acacia produces 23 million $\mathrm{m}^{3}$ in Indonesia in 2016 (Badan Pusat Statistik, 2017). It is mainly used for pulp chips, low specific gravity furniture, fuels, wood-based materials such as plywood and particle board (HKrisnawati et al., 2011). Due to the development of overseas forest resources, there is an urgent need to develop high-value-added products (construction materials, interior materials etc.) rather than low-valueadded products(wood chip, pellet, etc.).

In addition, bamboo materials which are non-wood materials produced in Indonesia, are mostly carbonized and used as fuel (Park et al., 2018; Sythud et al., 2015). Research on WPC and composite materials reinforced with bamboo fiber as a material having excellent compressive strength and bending strength is underway (Lee et al., 2002; Lee et al., 2018).

The purpose of this study is to confirm the possibility of using acacia with low strength among the tropical wood as a structural timber. This study is to investigate the feasibility of CLT as a large-size wood panel by evaluating the strength characteristics of CLT by using acacia and bamboo solid board.

\section{MATERIALS and METHOD}

\subsection{Testing materials}

\subsubsection{Acacia lamina}

Acacia (Acacia mangium Willd.) lumber(green condition) imported from Indonesia was obtained from A manufacture. The original dimension of the lumber was $1000 \mathrm{~mm}$ (Length) $\times 90 \mathrm{~mm}$ (Width) $\times 30 \mathrm{~mm}$ (Thickness). All lumber pieces produced SLP(Single Layer Panel) through kiln drying and 4 sided planning process with a Moisture content of less than $12 \%$ in $\mathrm{B}$ manufacture. The basic properties of acacia lamina are shown in Table 1. According to ANSI/APA PRG 320 (2018), it is possible to use lamina with a density of $0.35 \mathrm{~g} / \mathrm{cm}^{3}$ or more in the production of CLT. And it is confirmed that acacia lamina used in this study can be used as CLT material with $0.37 \mathrm{~g} / \mathrm{cm}^{3}$.

\subsubsection{Bamboo solid board}

The bamboo (Phyllostachys edulis) solid board to be used as the core material of CLT was $2,440 \mathrm{~mm}$ (Length) $\times 1,220 \mathrm{~mm}$ (Width) $\times 18 \mathrm{~mm}$ (Thickness) . The bamboo solid board was obtained from $\mathrm{C}$ manufacture. The basic physical properties of the bamboo solid board are shown in Table 1. 
Study on the Mechanical Properties of Tropical Hybrid Cross Laminated Timber Using Bamboo Laminated Board as Core Layer

Table 1. Physical and mechanical properties of materials

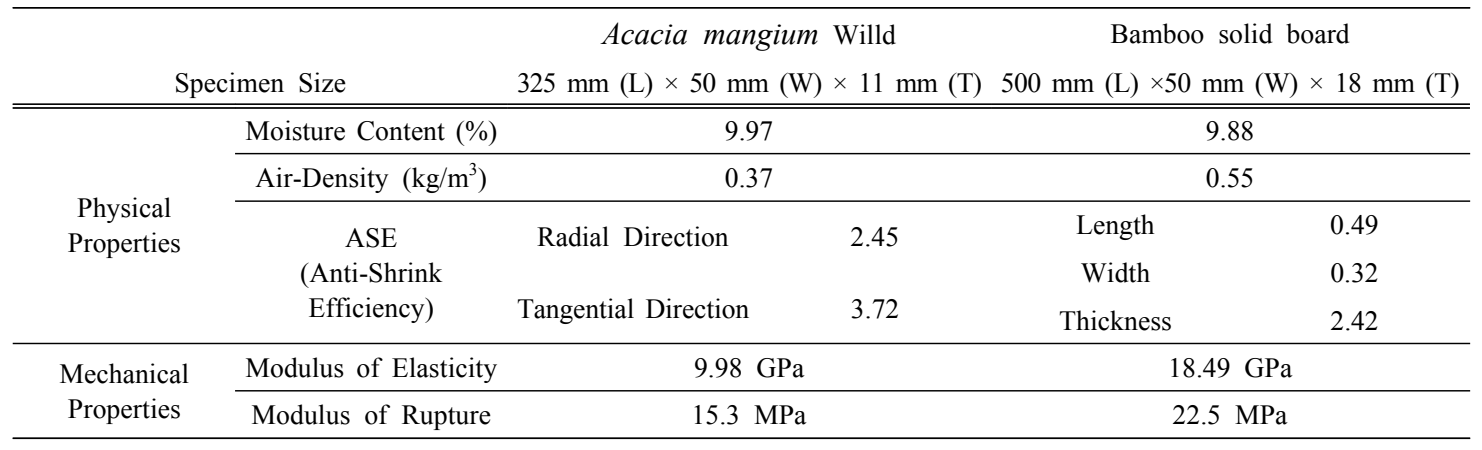

\subsubsection{Phenol-Resorcinol-Formaldehyde} (PRF)

Phenol-resorcinol-formaldehyde (PRF) adhesive (Oshika Co., Ltd., Tokyo, Japan) was used for the preparation of tropical hybrid CLT with the prepared acacia SLP (Single Layer Panel) and bamboo solid board. The adhesive properties and the applied amount are shown in Table 2.

\subsubsection{Manufacture of tropical hybrid CLT}

The tropical hybrid CLT was manufactured and
Table 2. Properties and Resin Level of phenolresorcinol-formaldehyde adhesive

\begin{tabular}{cccc}
\hline $\begin{array}{c}\text { Solid } \\
\text { content (\%) }\end{array}$ & pH & $\begin{array}{l}\text { Resin } \\
\text { Level }\end{array}$ & Hardener additive \\
\hline \hline $59.7 \%$ & 7.65 & $\begin{array}{c}300 \\
\mathrm{~g} / \mathrm{m}^{2}\end{array}$ & $\begin{array}{c}\text { Paraformaldehyde } \\
\text { 5\% adhesive solid content }\end{array}$ \\
\hline
\end{tabular}

comprises 3 layers with bamboo board as the core layer and the lumber of Acacia mangium Willd. as the outer layer (Fig. 1).

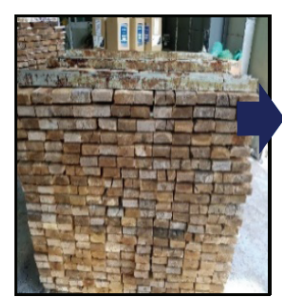

Drying process

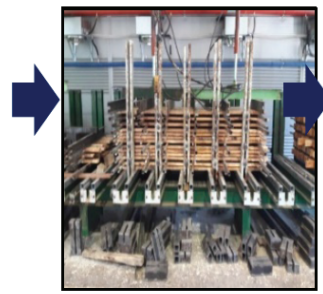

SLP production

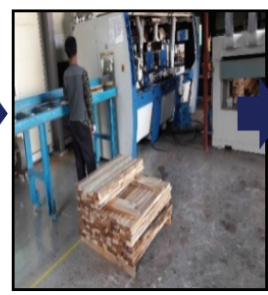

Lamination process

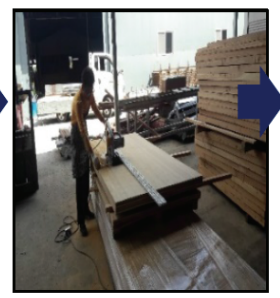

Bamboo board foundation

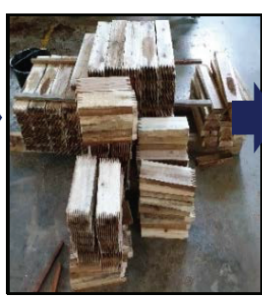

Finger joint

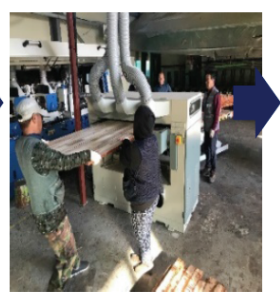

SLP planer

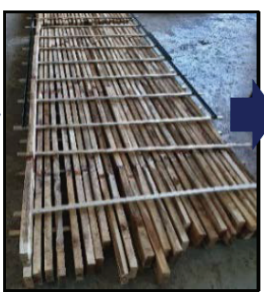

Finger joint press

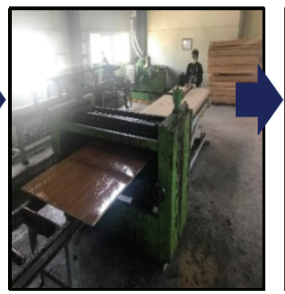

CLT production

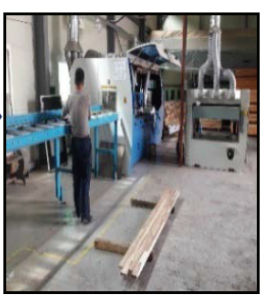

Layer rework

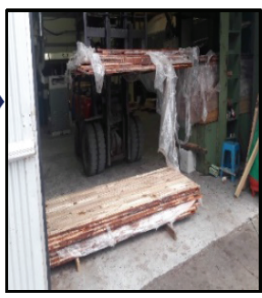

CLT foundation

Fig. 1. Tropical hybrid CLT manufacturing process in "H. Co., Ltd", Korea 


\subsection{Testing method}

\subsubsection{Analysis of tropical hybrid CLT strength properties}

For the analysis of strength characteristics of tropical hybrid CLT, bending strength and shear strength were measured according to ASTM D 198 Standard Test Methods of Static Tests of Lumber in Structural Sizes, as noted in APA PRG 320 2018. The specimen size and the number off repetitions of the test specimens are shown in Table 3 .

The load of bending strength was applied to the third-point loading and the load speed was 10 $\mathrm{mm} /$ minute. The load of shear strength was applied to the center-point loading and the load speed was 10 mm/minute. 10 Ton UTM (Universal Testing Machine Housefield H50K-ST Tinius Olsem Ltd, Redhill, England) was used for both testing procedures.

The MOE and MOR by the CLT bending strength test were calculated according to Eq. (1) and Eq. (2). The shear strength was calculated according to Eq. (3).

Calculating equation of Third point loading test according to bending strength

$$
\text { Modulus of Elasticity }(\mathrm{MOE})=\frac{23 P l^{3}}{108 b d^{3} \triangle}
$$

Modulus of Rupture (MOR) $=\frac{P_{\max } l}{b d^{2}}$

Table 3. Specimen size and repetition of tropical hybrid CLT

\begin{tabular}{cccc}
\hline & $\begin{array}{c}\text { Crosshead } \\
\text { speed }\end{array}$ & Specimen size Repetition \\
\hline \hline Bending strength & & $1260 \mathrm{~mm}(\mathrm{~L})$ & \\
(third point loading) & $10 \mathrm{~mm} /$ & $\times 54 \mathrm{~mm}(\mathrm{~T})$ & \\
\cline { 1 - 1 } $\begin{array}{c}\text { Shear strength } \\
\text { (center point }\end{array}$ & minute & $270 \mathrm{~mm}(\mathrm{~L}) \times$ & 12 \\
loading) & & $305 \mathrm{~mm}(\mathrm{~W}) \times$ & \\
\hline
\end{tabular}

Calculating equation of center point loading test according to shear strength

Shear Modulus of Elasticity

$$
=\frac{P l^{3}}{4 b d^{3} \triangle\left(1-\frac{3 P l}{10 b d G \triangle}\right)}
$$

1: span of specimen $(\mathrm{mm})$

b: width of specimen $(\mathrm{mm})$

$\mathrm{d}$ : depth of specimen $(\mathrm{mm})$

$\Delta$ : difference in center deflection $(\mathrm{mm})$

$\mathrm{P}$ : difference between upper limit load and lower limit load within proportional limit $(\mathrm{N})$

In order to calculate the rolling shear value, the modulus of elasticity of the material is required. However, in this study, the rolling shear value was calculated to be $1 / 10$ of the shear strength based on the CLT Handbook. The strength characteristics were evaluated for use as a CLT made from acacia and bamboo board which are tropical wood. SPF CLT, which is widely used in Europe, is selected and the data of strength characteristics are cited (Wang et al., 2017). For comparison with the tropical hybrid CLT result test, the MOE and MOR of SPF CLT was also shown in the result test. Canadian J-Grade SPF dimension lumber with a grade of $2.0 \mathrm{E}$ made of Douglas fir (Pseudotsuga menziesii) were purchased from a local market, as noted in the reference. The SPF lumber were $2.44 \mathrm{~m}(\mathrm{~L}) \times 89 \mathrm{~mm}(\mathrm{~W}) \times 38 \mathrm{~mm}(\mathrm{~T})$ in size. The SPF lumber and LVL panels had an average MC of $16 \%$ and $12 \%$, respectively, during the test. Onecomponent polyurethane adhesive (Purbond HB S709) was used to fabricate the CLT and HCLT specimens.

\section{RESULTS and DISCUSSION}

\subsection{Properties of tropical hybrid cross laminated timber}

\subsubsection{Bending strength of tropical hybrid cross laminated timber}

The moisture content and air dry density were 
Study on the Mechanical Properties of Tropical Hybrid Cross Laminated Timber Using Bamboo Laminated Board as Core Layer

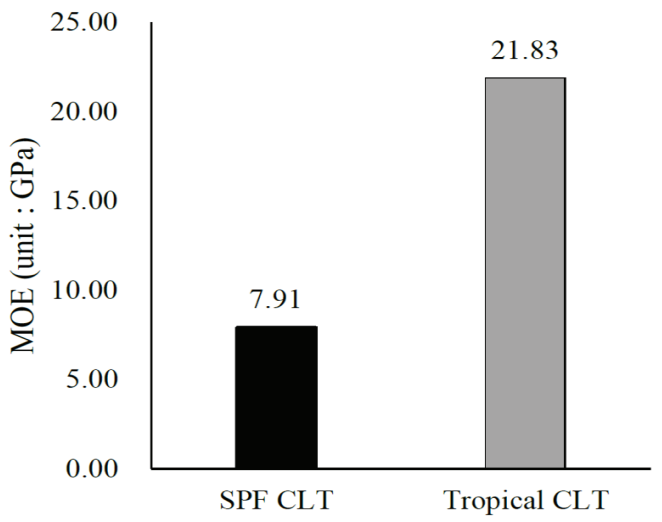

Fig. 2. MOEs of SPF CLT and tropical CLT

measured as basic properties of the tropical hybrid CLT produced by using acacia lamina and bamboo board. The moisture content of CLT was about $12 \%$ and the air dry density was $0.56 \mathrm{~g} / \mathrm{cm}^{3}$.

The MOE and MOR of the tropical hybrid CLT are shown in Figs. 2 and 3, respectively. The MOE of the tropical hybrid CLT was $21.83 \mathrm{GPa}$, as seen in Fig. 2, compared to the MOE of SPF CLT, which was 7.91 GPa. The MOE of the tropical hybrid CLT was 2.76 times higher compared to that of SPF CLT. As in Fig. 3, the MOR of the tropical hybrid CLT was $39.41 \mathrm{MPa}$ and that of SPF CLT was $28.60 \mathrm{MPa}$. The MOR of the tropical hybrid CLT was 1.37 times higher than that of SPF CLT.

The bending properties test showed that the tropical hybrid CLT had a better performance compared to SPF CLT due to its higher MOE and MOR. As shown in both graphs, the difference between the MOEs and MORs demonstrates the better performance of the hybrid CLT, made by Acacia lamina, compared to SPF CLT. The bamboo board, which has a high elasticity strength, on the core layer of the tropical hybrid CLT prevents the CLT from damage caused by the load pressure. The strength of the bamboo fiber on the bamboo board layer also prevents the cracks that can appear on the CLT surface (Liu et al., 2012; Inoue

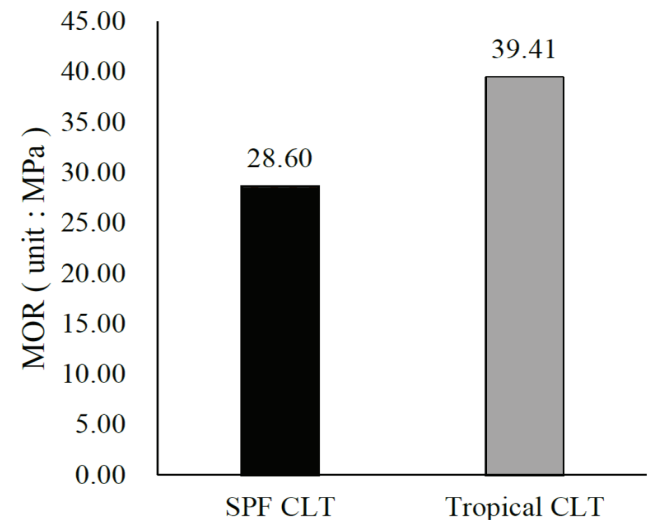

Fig. 3. MORs of SPF CLT and tropical CLT

et al., 2006). The low density of acacia wood provides an advantage of the hybrid CLT. The light weight will make easily the manufacturing and transportation processes. The failure type of the bamboo board showed the failure of the hybrid CLT after load bearing during the bending strength test. The cracks occurred on the edge side and propagated parallel to the fibers along the gluing line between the layers of acacia and bamboo board. On the board surface, failure occurred at the finger joint connection between the acacia wood. This cracks indicates the weakness of the CLT board when placed on a finger joint connection.

\subsubsection{Shear strength of tropical hybrid cross laminated timber}

The shear modulus, parallel to the grain of the tropical hybrid CLT, is shown in Fig. 4 and the rolling shear of the tropical hybrid CLT is shown in Fig. 5. The shear modulus was 69.29 MPa and the rolling shear was $6.93 \mathrm{MPa}$. The shear modulus of the tropical hybrid CLT was 0.8 times lower than that of SPF CLT. As in Fig. 5, the rolling shear of SPF CLT was $8.49 \mathrm{MPa}$ and the rolling shear of tropical hybrid CLT was 6.93 MPa. According to the CLT Handbook, the transverse shear modulus(G) is an assumption where the rolling shear modulus in the product standard was $1 / 10$ of the 


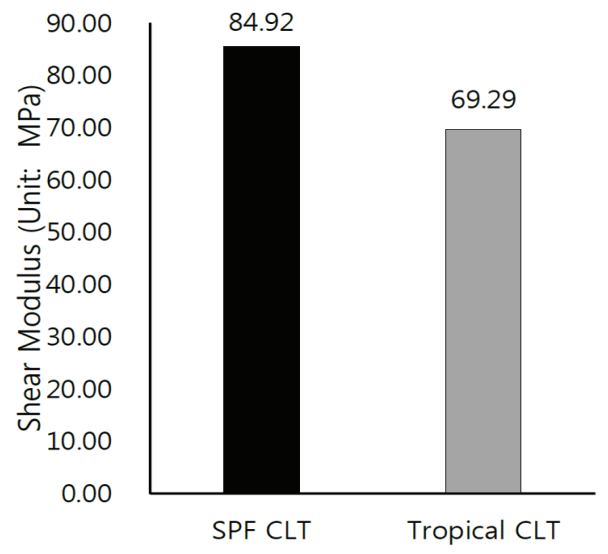

Fig. 4. Shear modulus of SPF CLT and tropical hybrid CLT

shear modulus parallel to the grain. The shear strength of the hybrid CLT shows that both the shear modulus and the rolling shear of tropical hybrid CLT were 0.8 times lower than those of SPF CLT.

The tropical hybrid CLT had a lower shear strength on both the shear modulus parallel to the grain and the rolling shear performance compared to those of SPF CLT. The rolling shear strength and stiffness in CLT has been identified as a key issue that controls the design and performance of CLT floor and wall systems. The rolling shear depends on species, cross-layer density, lamination thickness, $\mathrm{MC}$, sawing pattern configurations, and size of the lamination's cross-section, among others.

The failure type of the hybrid CLT after load-bearing in the shear strength test is shown in Fig. 6. The cracks occurred on the edges of the CLT, initiating from cracks in the planar shears. Afterward, the cracks spread along the longitudinal direction of the acacia layer. Then, they turn along the CLT surface, causing it great damage. The damage on the CLT surface indicates that the weakness of CLT is on the surface of the acacia layer and the hybrid CLT has a low on the rolling shear.

The high elasticity of the bamboo board as a core layer causes high tension on the CLT surface. It was confirmed that the tropical hybrid CLT has a low

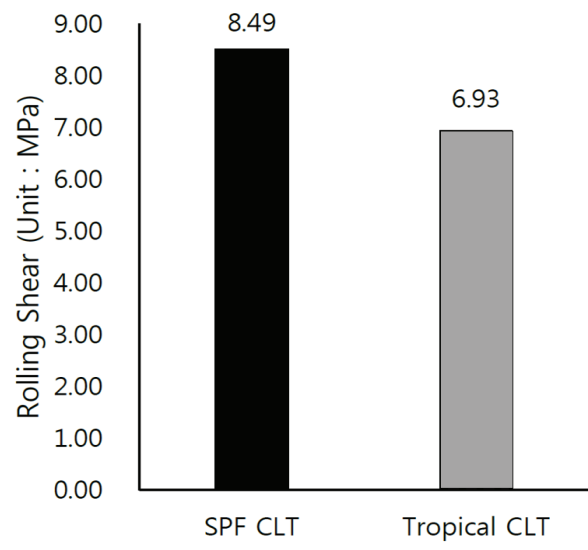

Fig. 5. Rolling shear strength of SPF CLT and tropical hybrid CLT

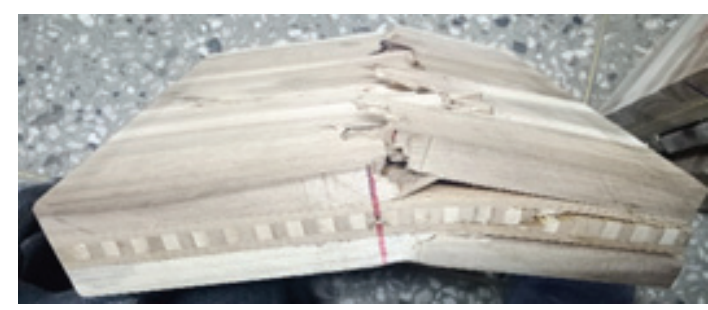

Fig. 6. Failure type of the tropical hybrid CLT after shear strength test

resistance against shear deformation compared to SPF CLT due to the low performance of shear strength. The bamboo board sustained a long crack along its edge side. As a structural material, the shear deformation has an important effect from shear properties. The amount of deformation will depend upon the loading and span-to-depth ratio, and will end fixity of the panels load performance capacity and the appearance of cracks on the CLT surface (CLT Handbook, 2013).

\section{CONCLUSION}

In this study, the bending strength and shear strength of the tropical hybrid CLT, with bamboo board as the core layer, were used to evaluate the mechanical properties of the tropical hybrid CLT performance using 
Study on the Mechanical Properties of Tropical Hybrid Cross

Laminated Timber Using Bamboo Laminated Board as Core Layer

Acacia mangium Willd. as a CLT lamination material.

The findings are as follows:

1. The bending strength test showed that the MOE of the tropical hybrid CLT was 2.76 times higher than that of SPF CLT. In addition, the MOR of the tropical hybrid CLT was 1.37 times higher than that of SPF CLT.

2. The shear strength test showed that the shear modulus parallel to the grain and the rolling shear of the tropical hybrid CLT were 0.8 times lower than that of SPF CLT. This is dependent upon the factor from the bamboo board.

3. Lumber of Acacia mangium Willd. from Indonesia can be used for CLT manufacturing as the lamination of CLT during manufacturing processing.

\section{ACKNOWLEDGEMENTS}

This study was carried out with the support of ' $R \& D$ Program for Forest Science Technology (Project No. 2019049B10-1919-BB02)' provided by Korea Forest Service(Korea Forestry Promotion Institute).

\section{REFERENCES}

Andi, S.R.D.L., Hadi, Y.S., Hermawan, D., Santoso, A. 2018. Physical and Mechanical Properties of Glued Laminated Lumber of Pine (Pinus merkusii) and Jabon (Anthocephalus cadamba). Journal of the Korean Wood Science and Technology 46(2): 143-148.

ANSI/APA. 2018. PRG 320 Standard for performancerated cross-laminated timber. APA-The engineered Wood Association, Tacoma, WA.

ASTM. D198. 2015. Standard test methods of static tests of lumber in structural sizes. American society of testing and materials (ASTM). West Conshohocken, PA.
Badan Pusat Statistik. 2017. Statistic of forest production. Jakarta, Indonesia.

Brandner, R., Flatscher, G., Ringhofer, A., Schickhofer, G., Thiel, A. 2016. Cross laminated timber (CLT): overview and development. European Journal of Wood and Wood Products 74: 311-351.

Choi, C., Yuk, C.R., Yoo, J.C., Park, J.Y., Lee, C.G., Kang, S.G. 2015. Physical and mechanical properties of cross laminated timber using plywood as core layer. Journal of the Korean Wood Science and Technology 43(1): 86-95.

Chio, C., Kojima, E., Kim, K.J., Yamasaki, M., Sasaki, Y., Kang, S.G. 2018. Analysis of mechanical properties of cross-laminated timber(CLT) with plywood using Korean larch. Bioresources 13(2): 2715-2726.

Choi, Y.S., Park, J.H., Lee, J.H., Shin, J.H., Jang, S.W., Kim, H.G. 2018. Preparation of EVA/Intumescent/ Nano-Clay Composite with Flame Retardant Properties and Cross Laminated Timber(CLT). Journal of the Korean Wood Science and Technology 46(1): 73-84.

Gong, M., 2019. Lumber-Based Mass Timber Products in Construction. Timber Buildings and Constructions. $1: 20$

Hegde, M., Palanisamy, K., Yi, J.S. 2013. Acacia mangium Wild: A Fast Growing Tree for Tropical Plantation. Journal of Forest Science 29(1): 1-14

Hong, M.K., Park, B.D., Kim, K.H., Shim, K.B. 2017. Performance of Melamine-Urea-Formaldehyde Resin Adhesives at Various Melamine Contents for Bonding Glued Laminated Timber Under High Frequency Heating. Journal of the Korean Wood Science and Technology 45(4): 409-418.

Inoue, M., Park, K.G. 2006. Application of new connecting system of wood structures using bamboo connector. Journal of the Korean Association for Spatial Structures 6(2): 7-12.

Kang, C.W., Jang, S.S., Kang, H.Y., Li, C. 2019. Sound 
Absorption Rate and Sound Transmission Loss of CLT Wall Panels Composed of Larch Square Timber Core and Plywood Cross Band. Journal of the Korean Wood Science and Technology 47(1): 33-39.

Korea Forest Service. 2019. Overseas Plantation Status (http://forest.go.kr/newkfsweb/html/HtmlPage.do? $\mathrm{pg}=/$ resource/resource_050502.html\&mn=KFS_02 _01_06_05_02)

Krisnawati, H., Kallio, M., Kanninen, M. 2011. Acacia Mangium Wild.: Ecology, Silviculture and Productivity. CIFOR, Bogor, Indonesia.

Lee, B.H., Jeong, D.S., Kim, C.W., Park, S.H., Kim, Y.C. 2018. Influence of the chemical treatment of bamboo fiber(BF) on physical properties of $\mathrm{BF}$ and PP/PE composites. Applied Chemistry for Engineering 29(2): 168-175.

Lee, H.H., Han, K.S., Kim, G.E. 2002. Characteristics of particleboards made from three-months-old domestics bamboo(Phyllostacbys nigra var benonis stapf). Journal of the Korean Wood Science and Technology 30(1): 11-17.

Lee, I.H., Song, Y.J., Hong, S.I. 2017. Evaluation of The Moment Resistance of Reinforced Wooden Gusset to Glulam Joint. Journal of the Korean Wood Science and Technology 45(1): 53-61.

Lee, I.H., Song, Y.J., Hong, S.I. 2017. Evaluation of Moment Resistance of Rigid Frame with Glued Joint. Journal of the Korean Wood Science and Technology 45(1): 28-35.

Liu, D.G., Song, J.W., Anderson, D.P., Chang, P.R., Hua, Y. 2012. Bamboo fiber and its reinforced composites: structure and properties. Cellulose 19: 1449-1480.

MGB Architecture and Design, Equilibrium Consulting, LMDG Limited, BTY Group. 2012. The case for tall wood buildings, British Columbia, Canada.
Oh, J.K., Kim, G.C., Kim, K.M., Lee, J.J., Hong, J.P. 2017. End Distance of Single-shear Screw Connection in Cross Laminated Timber. Journal of the Korean Wood Science and Technology 45(6): 746-752.

Pang, S.J., Kim, K.M., Park, S.H., Lee, S.J. 2017. Bending Behavior of Nailed-Jointed Cross-Laminated Timber Loaded Perpendicular to Plane. Journal of the Korean Wood Science and Technology 45(6): 728-736.

Park, S.H., Jang, J.H., Wistara, N.J., Hidayat, W. 2018. Anatomical and Physical Properties of Indonesian Bamboo Carbonized at Different Temperatures. Journal of the Korean Wood Science and Technology. 46(6): 656-669.

Robertson, A. 2007. A comparative life cycle assessment of mid-rise office building construction alternatives : Laminated timber or reinforced concrete. Master's Thesis, University of Toronto, Canada.

Son, Y.M., Kim, H., Lee, H.Y., Kim, C.M., Kim, C.S., Kim, J.W., Joo, R.W., Lee, K.H. 2010. Stand yield table and commercial timber volume of eucalyptus pellita and acacia mangium plantations in Indonesia. Journal of Korean Forestry Society 99(1): 9-15. Song, Y.J., Hong, S.I. 2016. Evaluation of Bonding Strength of Larch Cross-Laminated Timber. Journal of the Korean Wood Science and Technology 44(4): 607-615.

Sythud, P., Zhang, Y., Mukete, B. 2015. Bamboo Resources Utilization : A Potential Source of Income to Support Rural Livelihoods. Applied Ecology and Environmental Science 3(6): 176-183.

Wang, Z., Fu, H., Gong, M., Luo, J., Dong, W., Wang, T., Chui, Y.H. 2017. Planar shear and bending properties of hybrid CLT fabricated with lumber and LVL. Construction Building Materials. 151: 172-177. 